\title{
Study on the Cultivation of Toughness Personality of Higher Vocational College Students Based on Positive Psychology
}

\author{
Lu Yang \\ Liaoning Jianzhu Vocational College, Liaoyang, Liaoning, 111099
}

Keywords: positive psychology; toughness personality; vocational college students

\begin{abstract}
Positive psychology is a new trend of research in psychology. It uses the comparatively perfect and effective measurement methods and experimental methods in psychology to study the virtues and strength of human beings. Higher vocational college students are in an important period of life, and they need to face major and rapid changes in the aspects of physiology, psychology, and environment, and to withstand the pressure from their academic, interpersonal, emotional and other aspects, especially in the junior year. The personality problems during graduation and employment is called the crisis of life. In addition, the current Chinese society is in a period of economic transition, and these directly affect the development of the tough personality of higher vocational college students.
\end{abstract}

\section{Introduction}

To strengthen the mental health education of students in vocational colleges and improve the mental health of higher vocational college students is beneficial to their lifelong development and conducive to the all-round development of higher vocational students. Specialist education and general higher education are two completely different types of education. Vocational education aims at cultivating students' practical ability. The purpose is to cultivate the practical ability of higher vocational students. Although higher vocational college students belong to the category of higher education students, they face more pressure from physical, psychological, education, employment, and interpersonal relationships than those of ordinary university students. China is currently in a period of economic transformation and comprehensive social reform. Social forms and functions are in the stage of constant adjustment and upgrading. Student employment faces enormous pressure. Higher vocational education is the period of turbulent development of young people's life. It is not stable in all aspects. These can directly affect their physical and mental health. Most vocational students of vocational colleges can overcome these pressures, complete their studies, and find an ideal job when they graduate. A small number of students cause mental illness when facing social reality and academic pressure. What exactly makes higher vocational college students face different results in the face of these pressures: Some individuals can maintain health, and some individuals have physical or psychological diseases? Some researchers pointed out that it is because there are certain personality traits among individuals that can protect people's physical and mental health. The most studied by Western researchers is the protection of the individual's body and mind by a resilient personality. In 1979 the concept of tough personality was proposed. It has been studied to find out the role of tough personality, which can help individuals experiencing life and work stress to maintain their physical and mental health, and buffer the adverse physical and psychological impact of external pressure on the individual.

\section{Concept of Toughness Personality}

In recent years, the research on tough personality has been increasing. Many researchers have expanded their connotations and proposed their own understanding of the concept of firm personality. Research on tough personality has become more sophisticated and more and more defined. Taking into account the differences between Chinese and Western cultures, it is difficult to define a firm personality. The study chose Lu Guohua's definition of tough personality. Lu Guohua, 
a domestic scholar, believes that tough personality is an upward positive personality quality that integrates knowledge, affection, intention, and behavior. There are four dimensions in the initial personality of the Chinese: input, control, challenge, and earlyness. Input is the concentration of individual behavioral activities; control is the ability of individuals to actively control and influence the events they experience; challenge is the trait reflecting whether individuals can be courageous to accept challenges and grow in challenges; Individuals face difficulties, optimism, and perseverance in the pursuit of goals.

The connotation of the initial personality is mainly composed of three dimensions. These three dimensions are interconnected. The three dimensions are: commitment, control, and challenge. Their English is: It is precisely because the three dimensions of English begin with a letter, and researchers call it a tough structure. The concrete meaning of the three dimensions is as follows: The first commitment dimension refers to the individual's life, work, and interpersonal relationships that he can dedicate himself to, and actively explores the fun and meaning of life, rather than escaping. The second control dimension refers to the means of control under adverse conditions. Individuals believe that they can change the development of the situation through their own actions. Under such guidance, individuals actively act and work hard to influence the situation as the situation changes. Instead of making himself a victim of the environment. The third challenge dimension refers to social individuals who learn from their own life experiences, whether they are positive or negative life experiences. In short, see change as a normal form of life and see difficulties as a challenge rather than a threat to your growth.

\section{The Current Status and Causes of Toughness Personality of College Students}

The problem of students' initial personality in higher vocational colleges has brought about obvious harm to higher vocational college students. These hazards have affected the development of their potential and have become a major obstacle to the success and development of higher vocational students. These obstacles have gradually developed into a personality problem or personality flaws, and there may be a tragedy of student crimes or murders. The concept of firm personality was first proposed. A study conducted by Mardi shows that after training, the participants not only had a significant improvement in job satisfaction, but also had a significant improvement in their job satisfaction. At the same time, the subjects were trained to have anxiety, depression, and blood pressure. The decline. It is proposed that the establishment of a firm personality can have a protective effect on the physical and mental health of individual individuals. At the same time, it can also regulate the effects of life stress on individuals and alleviate the destructive effects of stress on individuals. There are two main ways to positively modulate the physical and mental health of an individual. The first is that toughness can be adjusted through social support to increase the likelihood of social individuals' successful and active responses; the other way is that social individuals directly draw positive results. Coping strategies to reduce destructive stress events. Therefore, vocational vocational students' vocational training needs to find the most fundamental reason for higher vocational students. This requires a systematic analysis of the tough personality of higher vocational college students from the angles of society, school, family, and individuals.

Today, China is in a special period of economic transformation and vigorous economic development. There are criss-crossed values in society. Since there are differences in the growth environment and cultural levels between individuals, different people have different understandings of the same issue. the same. With the continuous deepening of China's market economy, rapid economic development, and wider exchanges between Eastern and Western cultures, the influence of Western cultural values on the lives of Chinese people has become increasingly apparent. The conflict of ideas between Chinese and Western cultures has also become unprecedented. Some typical ideas in the West invade China, such as democracy and freedom, interests are supreme, money first, etc. The idea of quick success and instant benefit is recognized by the Chinese people. These concepts cause Chinese students to be confused in their outlook on life and lose themselves. In addition, most of the students in vocational colleges do not have a certain ability to identify. If 
they do not properly select these mixed information, they will easily form incorrect values. In addition, the current economic development brought about by the fast pace of life, talent competition is too fierce to make vocational students feel nervous, this social ethos easily lead to the overall level of toughness of higher vocational college students is not high.

The school plays an irreplaceable role in forming the tough personality of higher vocational students, because the school is the main environment for students in vocational schools. Whether or not it can help students establish correct values in a timely manner and the status of school education play a decisive role. Although school education is unique compared to other forms of education, higher vocational colleges still fail to cultivate the students' Weiwei edge personality education. So far it has not been able to help students avoid problems in a timely and effective manner. For example, there are problems in the current education of the college students with strong personality in school education, there is insufficient education in the strong personality, education content and the actual situation of the students want to break away, education methods behind. First of all, tough personality education is not in place. Most vocational colleges do not pay enough attention to students' tough personality education. Compared with other forms of education, school education has some unique advantages. However, as vocational colleges have not yet made good use of these resources, the result is that vocational colleges are generally lacking in students' tough personality education. Second, the psychological support team is not professional, the quality of the service needs to be improved, and the effectiveness of personality education is not effective. In terms of teaching content, higher vocational colleges pay more attention to teaching students' cultural knowledge and skill operation. Relatively ignoring students' personality education is a lack of steadfast personality training for students in school. Moreover, the education methods for tough personality in higher vocational schools are relatively backward. The personality education of students generally belongs to moral education. Since moral education has long adopted the traditional classroom teaching, it has been separated from the students' thinking points, and the form of teaching has been single, resulting in little effective results. At present, in the actual teaching of personality education in higher vocational colleges and universities, schools basically do not provide students with the opportunity and space for strong personality education exchange and interaction. Therefore, school education has a strong personality in the cultivation of higher vocational students. It is difficult to achieve better results.

\section{Training Plan of Resilience Personality Vocational College Students}

The power of the media is so great that media workers must consider issues in various ways. They must not only learn to report facts objectively but also realize the impact of their work on society and shoulder the mission of stimulating positive social energy. While exposing the dark side of society, we also made everyone understand that what should be improved in order to make society more sunny, but also to report more positive and beautiful aspects, and to create a positive social organization system to promote the active development of individuals. For example, since the beginning of the year, China has held "Empressed China - People of the Year" selection each year. These selected moving people are some of the most distinguished experts from different fields in society, some are ordinary people, but they all have one thing in common. That is, everyone has a power that shakes the soul. For example, Zhang Lili, the most beautiful teacher of the year, has caused her to be crushed by trucks and rescue her at a high level because of the rescue of students in car accidents. It is the influence and radiation of these moving characters that immediately followed by the emergence of more and more mortals, good people, and teachers who sacrificed for the sake of saving students in the earthquake. They insisted on inspecting railways for decades to protect railway safety. The railway policemen have also devoted their lives to the scientific research of the nation's scientists. The firm-minded personalities they display have converged into positive energy for positive people and continuously promote the development of positive social organizations.

The school is the main base for students' resilience personality cultivation. The school plays an important role in the cultivation of higher vocational students' initial personality. Higher vocational colleges have two teaching goals: one is to teach the professional knowledge of the vocational 
school students and various operating skills, the other is to develop the comprehensive quality of vocational school students so that they can fully develop. Under the premise that teaching tasks are completed, vocational colleges must establish a sound and resilient personality training program based on the inherent laws of the formation and development of higher vocational students in order to strengthen the education of the key personality of higher vocational college students. Strengthen the commitment dimension of students' initial personality, strengthen tough personality training to enhance their control dimensions, and develop outdoor sports to enhance the initial and challenging dimensions of tough personality of higher vocational college students.

\section{Conclusion}

We can see the significance of students in higher vocational colleges in exploring the initial personality. The Ministry of Education is also paying more and more attention to mental health education. Quality education is also on the agenda. Higher vocational college students as a special group of college students, compared with ordinary university students, are facing more pressure on their own body and mind and employment. China is currently undergoing economic restructuring, comprehensive social reforms, and increasingly fierce competition in education and employment, which is the development of turbulent periods in which higher vocational college students have increased pressure to directly affect their healthy lives. Kennedy can cushion the adverse effects of stress on personal health, and help people maintain their work pressure through various life support and physical and mental health. This study explores the cultivation of personality perseverance of higher vocational students from the perspective of positive psychology.

\section{References}

[1] Chen Zhenhua. An Outline of Active Education [J]. Journal of East China Normal University (Educational Science Edition). 2009 (03)

[2] Liu Liquan, Xiao Dongmei. Positive, Hope, Happiness, and Happiness: Enlightenment of Positive Psychology on Ideological and Political Education for College Students [J]. Academic Forum. 2009 (07)

[3] Cui Jinggui. Characteristics and Evaluation of Positive Psychotherapy Paradigm in Germany [J]. Journal of Ningbo University (Educational Science Edition). 2009 (03)

[4] Zhu Jiguang. Exploration of happiness in college students' ideological and political education from the perspective of positive psychology [J]. Beijing Education (Moral Education). 2009 (01)

[5] Meng Wanjin. On Active Mental Health Education [J]. Educational Research. 2008 (05) 